\title{
Copy number variants in a sample of patients with psychotic disorders: is standard screening relevant for actual clinical practice?
}

This article was published in the following Dove Press journal:

Neuropsychiatric Disease and Treatment

II July 2012

Number of times this article has been viewed

\author{
Noortje WA Van de \\ Kerkhof' \\ Ilse Feenstra ${ }^{2}$ \\ Frank MMA van der \\ Heijden' \\ Nicole de Leeuw ${ }^{2}$ \\ Rolph Pfundt ${ }^{2}$ \\ Gerald Stöber ${ }^{5}$ \\ Jos IM Egger ${ }^{1,3,4}$ \\ Willem MA Verhoeven ${ }^{1,6}$ \\ 'Vincent van Gogh Institute for \\ Psychiatry, Centre of Excellence \\ for Neuropsychiatry, Venray, The \\ Netherlands; ${ }^{2}$ Radboud University \\ Nijmegen Medical Centre, \\ Department of Human Genetics, \\ Nijmegen, The Netherlands; ${ }^{3}$ Donders \\ Institute for Brain, Cognition and \\ Behaviour, ${ }^{4}$ Behavioural Science \\ Institute, Radboud University, \\ Nijmegen, The Netherlands; \\ ${ }^{5}$ University of Würzburg, Department \\ of Psychiatry, Psychosomatics and \\ Psychotherapy, Würzburg, Germany; \\ ${ }^{6}$ Erasmus University Medical Centre, \\ Department of Psychiatry, Rotterdam, \\ The Netherlands
}

Correspondence: NWA Van de Kerkhof Vincent van Gogh Institute for Psychiatry, Centre of Excellence for Neuropsychiatry, Stationsweg 46, 5803 AC Venray, The Netherlands Tel +3I 478527339

Fax +31 478527110

Email nvandekerkhof@vvgi.nl

\begin{abstract}
With the introduction of new genetic techniques such as genome-wide array comparative genomic hybridization, studies on the putative genetic etiology of schizophrenia have focused on the detection of copy number variants (CNVs), ie, microdeletions and/or microduplications, that are estimated to be present in up to $3 \%$ of patients with schizophrenia. In this study, out of a sample of 100 patients with psychotic disorders, 80 were investigated by array for the presence of CNVs. The assessment of the severity of psychiatric symptoms was performed using standardized instruments and ICD-10 was applied for diagnostic classification. In three patients, a submicroscopic CNV was demonstrated, one with a loss in 1q21.1 and two with a gain in 1p13.3 and 7q11.2, respectively. The association between these or other CNVs and schizophrenia or schizophrenia-like psychoses and their clinical implications still remain equivocal. While the CNV affected genes may enhance the vulnerability for psychiatric disorders via effects on neuronal architecture, these insights have not resulted in major changes in clinical practice as yet. Therefore, genome-wide array analysis should presently be restricted to those patients in whom psychotic symptoms are paired with other signs, particularly dysmorphisms and intellectual impairment.
\end{abstract}

Keywords: schizophrenia, psychotic disorders, microarray, copy number variants, 1q21, $7 \mathrm{q} 11.2,1 \mathrm{p} 13.3$

\section{Introduction}

It has become obvious that the phenotypical presentation of psychotic disorders such as schizophrenia is extremely heterogeneous and that their symptoms may comprise the entire spectrum of psychopathology with high interindividual variation. ${ }^{1,2}$ Although the diagnostic boundaries of schizophrenia still remain unclear, the worldwide lifetime prevalence of this psychotic disorder is estimated to be $0.5 \%-1 \%{ }^{3}$ Previous studies have shown a heritability varying from $40 \%-70 \%,{ }^{4}$ and a family history of schizophrenia has been demonstrated to be the far most important risk factor. ${ }^{5,6}$ Over the past years, substantial evidence has emerged concerning the relevance of gene-environment interactions for the onset and course of schizophrenia. ${ }^{7,8}$

With the ongoing developments in genetic techniques, particularly array-based comparative genomic hybridization analysis, it has become possible to investigate the human genome in far greater detail than is possible with routine cytogenetic analysis, leading to the discovery of previously undetectable defects. ${ }^{9}$ These so-called copy number variants (CNVs) are deletions or duplications ranging in size from $1 \mathrm{~kb}$ to $3 \mathrm{Mb}$ resulting in loss or gain of a DNA segment. De novo microdeletions are generally considered of clinical significance and are frequently associated with 
intellectual disability. ${ }^{10}$ Of these patients, a substantial percentage develop symptoms from the affective and/or psychotic cluster after adolescence. Microdeletions and duplications may also be causatively involved in patients with normal intelligence and psychiatric disorders like schizophrenia ${ }^{11,12}$ or autism. ${ }^{13,14}$ In his review, Kirov ${ }^{15}$ calculated a collective rate of $3 \%$ of patients with schizophrenia in whom rare deletions in 1q42, 22q11, and 1q21 and duplications in 16p are found. In the general population, this percentage is estimated to be $0.1 \%-1 \%$. ${ }^{16}$ The explanatory power of CNVs for the pathophysiology of psychiatric disorders in general and for their phenotypical presentation, however, still needs to be clarified. ${ }^{17,18}$

In the present study, genome-wide array analysis was performed in a group of patients with carefully diagnosed psychotic disorders in order to detect possible pathogenic CNVs. If present, their phenotypical relevance was explored and discussed.

\section{Methods}

\section{Patients and assessments}

Over a period of 30 months, 100 patients referred to the Vincent van Gogh Institute for Psychiatry for treatment of psychotic symptomatology were investigated. Patients with previously demonstrated cytogenetic aberrations and/or intellectual disability (IQ < 70) were excluded. According to the medical ethical guidelines, 80 patients gave written informed consent and 20 refused further participation (CCMO registration number: NL20469.097.07). Assessment of symptomatology and collection of data from history was performed using Comprehensive Assessment of Symptoms and History (CASH), ${ }^{19}$ Positive and Negative Syndrome Scale (PANSS),${ }^{20}$ and Clinical Global Impression Scale (CGI). ${ }^{21}$ Final clinical diagnoses were made in a so-called Longitudinal Evaluation using All Data (LEAD) conference. ${ }^{22}$ Subsequently, patients were classified according to the International Statistical Classification of Disease and Related Health Problems, 10th Revision (ICD-10) criteria. ${ }^{23}$ The main characteristics of the patients including the classification of their psychotic disorders are presented in Table 1. Pictures were taken of all patients for evaluation of dysmorphisms by an experienced clinical geneticist (IF). In case CNVs were found by array, the patient was examined in detail by the clinical geneticist.

\section{Genetic analyses}

DNA was isolated from an ethylenediaminetetraacetic acid (EDTA) blood sample and genome wide array analysis was performed with an average resolution of $200 \mathrm{~kb}$ using the
Table I Main characteristics of the patients $(n=80)$

\begin{tabular}{lll}
\hline & N & $\%$ \\
\hline Male/female & $53 / 27$ & $66 / 34$ \\
Mean age/range (years) & $35.0 / 18-62$ & \\
Mean age at onset of psychosis/range (years) & $27.1 / 9-6 I$ & \\
Mean number of episodes/range & $2.8 / 1-15$ & \\
Diagnoses (ICD-10) & & \\
Schizophrenia & 50 & 62.5 \\
Schizoaffective disorder & 6 & 7.5 \\
Acute and transient psychotic disorder & $1 \mathrm{I}$ & 13.8 \\
Bipolar disorder (psychotic) & 6 & 7.5 \\
Other psychotic disorders & 7 & 8.8 \\
PANSS scores (range) at inclusion & & \\
Total score & $86.1(46-138)$ & \\
Positive subscale & $23.1(11-37)$ & \\
Negative subscale & $19.9(7-40)$ & \\
Global subscale & $43.0(22-67)$ & \\
Mean CGI score (range) & & \\
Severity & $4.5(2-7)$ & \\
\hline
\end{tabular}

Abbreviations: PANSS, Positive and Negative Syndrome Scale; CGI, Clinical Global Impression Scale; ICD-10, International Statistical Classification of Disease and Related Health Problems, 10th Revision.

Affymetrix $250 \mathrm{k}$ SNP array platform (Affymetrix, Santa Clara, CA) as described previously. ${ }^{24}$

\section{Results}

As Table 1 shows, 50 patients fulfilled the criteria for schizophrenia (F20) and in 11 patients, a diagnosis of acute and transient psychotic disorder was made (F23). A diagnosis of schizoaffective disorder (F25) was established in six patients whereas in another six, bipolar affective disorder, current episode manic with psychotic symptoms, was present (F31.2). In the remaining seven patients, various diagnoses were made (F29, $\mathrm{n}=1 ; \mathrm{F} 28, \mathrm{n}=2 ; \mathrm{F} 22, \mathrm{n}=3 ; \mathrm{F} 21, \mathrm{n}=1$ ). All patients received antipsychotic medication according to the hospital standards.

If screening for dysmorphic features suggested a particular monogenetic disorder, specific genetic tests were performed. However, no abnormalities were disclosed. In 77 patients, microarray analysis did not reveal any abnormalities. In three patients, a submicroscopic chromosome imbalance was detected.

Patient A presented with a subacute onset of psychotic symptoms (total scores on PANSS and CGI-S were 79 and 4 , respectively) that remitted within 1 month after treatment with $2.5 \mathrm{mg}$ haloperidol. Her history disclosed no major somatic or psychiatric diseases and there was no family load with neuropsychiatric or genetic disorders. In her, an interstitial loss of $3.5 \mathrm{Mb}$ in 1q21.1 comprising 45 genes was found (Figure 1A). Patient B had a history of a mild and short-lasting psychotic episode 1 year before and did 

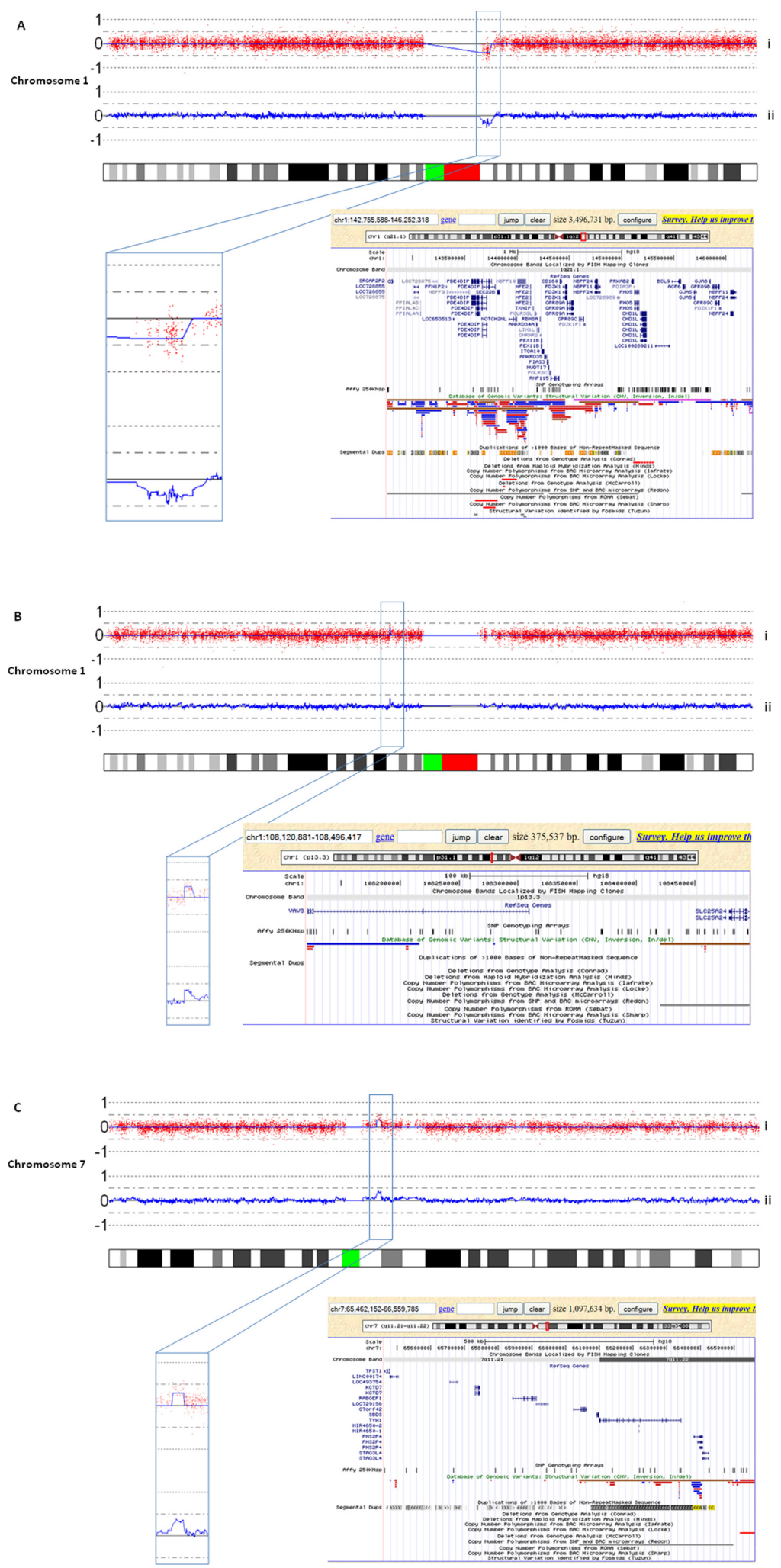

Figure I In the upper panel (i) of each plot $(\mathbf{A}-\mathbf{C})$, the log2 test over reference ratio is plotted on the $y$-axis against the genomic Mb position from pter to qter on the respective chromosome represented by the idiogram on the $\mathrm{x}$-axis in the lower part of each figure.

Notes: Each red dot represents the average value for a certain SNP probe. The normal ratio with value 0 is indicated by the solid, horizontal blue line. Values for normal ratios range between -0.38 and +0.3 . Values outside this range are considered abnormal. ${ }^{39}$ In panel (ii), the thick blue line represents the average of ten neighboring SNP probe values. In each figure, the aberrant chromosomal region is indicated by a rectangle that is enlarged in the lower left side of that figure. The gene content, $250 \mathrm{k}$ SNP array probe coverage, structural variation and segmental duplications of the aberrant chromosomal region is shown in the lower right side of the figure (screen shot of the Human March 2006 (hgl8) Assembly of the UCSC genome browser, http://genome.ucsc.edu/). In A, the interstitial 3.5 Mb loss in Iq2I.I of patient A is shown. In B, the interstitial gain in IpI3.3 (375 kb) detected in patient B is shown, and in C, the I.I Mb interstitial gain in $7 \mathrm{q} I \mathrm{I} .2 \mathrm{IqI} I .22$ of patient $\mathrm{C}$ is shown. 
not use any psychotropics. Apart from atypical psychotic symptoms, there were mild manic symptoms (total scores on PANSS and CGI-S were 78 and 5, respectively). With a treatment regimen comprising risperidone (4 $\mathrm{mg}$ daily) and lithium (1600 mg daily), all symptoms gradually resolved within 3 months. Here, a $375 \mathrm{~kb}$ interstitial gain in band p13 of chromosome 1 encompassing two genes was detected (Figure 1B). Patient $\mathrm{C}$ had neither a history of any psychiatric or somatic disease nor a family load with neuropsychiatric or genetic disorders. Shortly prior to admission he developed paranoid psychotic symptoms (total scores on PANSS and CGI-S were 63 and 2, respectively) which fully remitted after 1 month of treatment with risperidone $4 \mathrm{mg}$ daily. He had a 1.1 Mb interstitial gain in 7q11.21q11.22 containing 11 genes (Figure 1C).

It remained unclear whether these $\mathrm{CNV}$ s had occurred de novo, since in none of the patients blood samples of the parents were available for carrier testing. A concise description of psychiatric and somatic phenotypes as well as ICD-10 classification is presented in Table 2 .

\section{Discussion}

In three out of the 80 patients with psychotic disorders (3.75\%), one loss and two gains $>250 \mathrm{~kb}$ were detected which is in accordance with the report by Kirov who calculated a collective percentage of $3 \% \mathrm{CNVs}$ in schizophrenia. ${ }^{15}$

Apart from the recent report by Maiti et al, ${ }^{25}$ who found three de novo CNVs (two gains and one loss) in 7q11.21 in two families with monozygotic twins discordant for schizophrenia in which, however, the breakpoints of these CNVs do not overlap with those in patient $\mathrm{C}$, there is virtually no literature on the clinical significance. We recently detected a larger, completely overlapping gain of $2.4 \mathrm{Mb}$ in $7 q 11.21$ in a prenatal sample and the healthy father of this fetus with congenital diaphragmatic hernia. This makes it less likely that this gain is of clinical relevance.
With respect to $1 \mathrm{p} 13.3$, only Ohtsuki et al reported on a possible association with the netrin G1 (NTNG1) gene, located at 1p13.3, in Japanese families. ${ }^{26}$ This does not, however, apply to patient $\mathrm{B}$, nor does it clarify his symptom profile. Its relevance is further challenged by the detection of an exactly similar gain in 1p13.3 (in addition to a pathogenic, de novo duplication in 10q) in an intellectually disabled patient without any psychiatric symptoms who inherited this gain from his healthy father (unpublished data).

Microdeletions in the 1q21 region have been reported in several genome-wide analyses in large populations. ${ }^{27,28}$ A possible relationship between 1q21 and psychotic symptoms was reported by three research groups. ${ }^{29-31}$ Maiti et al reported on two de novo CNVs in families with monozygotic twins discordant for schizophrenia. ${ }^{25}$ Several genes are mapped on 1q21, such as the $K C N N 3,{ }^{32} N O T C H 2 N L,{ }^{25}$ and Connexin 40/50. ${ }^{33}$ Associations of these specific genes with schizophrenia in affected patients so far remain equivocal.

The results from this relatively small study using genomewide array analysis do not differ essentially from the reported large scale studies. It has to be stressed that the commonly applied diagnostic categories, derived from the ICD or Diagnostic and Statistical Manual of Mental Disorders systems, show no relationship to a specific genetic etiology. Moreover, a single gene defect never codes for a categorical psychiatric disorder, but may lead to a biological dysfunction that has a certain probability to be associated with the development of an array of psychiatric symptoms. ${ }^{14,17,18}$ This can best be illustrated by the discovery of the DISC1 gene in one family that was originally thought to be causally related to schizophrenia, ${ }^{34}$ but later appeared to be involved in a biochemical cascade with consequences for neuronal functions predisposing for psychiatric symptoms across diagnostic boundaries. ${ }^{35,36}$

Although the CNVs detected in three out of 80 patients are not likely to be primarily involved in the evolution of their psychotic disorders, systematic genetic analysis in patients

Table 2 Phenotype of the three patients with a potentially pathogenic CNV

\begin{tabular}{|c|c|c|c|c|}
\hline Patient & Psychiatric phenotype & Somatic phenotype & ICD-I 0 diagnosis & CNV \\
\hline A (6I-year-old female) & $\begin{array}{l}\text { Pananxiety, religious delusions, } \\
\text { delusions of influence, catastrophic } \\
\text { thoughts, olfactory and auditory } \\
\text { hallucinations }\end{array}$ & $\begin{array}{l}\text { Dysplastic ear helices, } \\
\text { length and head } \\
\text { circumference } \\
<2.5 \mathrm{SD}\end{array}$ & $\begin{array}{l}\text { Acute polymorphic psychotic } \\
\text { disorder without symptoms } \\
\text { of schizophrenia }\end{array}$ & $\begin{array}{l}3.5 \mathrm{Mb} \text { loss in } \\
\text { Iq2 I.I }\end{array}$ \\
\hline B (36-year-old male) & $\begin{array}{l}\text { Pressure of speech, misrecognition } \\
\text { of persons, thought incoherence, } \\
\text { transient visual misinterpretations }\end{array}$ & No dysmorphisms & $\begin{array}{l}\text { Schizoaffective disorder, } \\
\text { manic type }\end{array}$ & $\begin{array}{l}375 \text { kb gain in } \\
\text { IpI3.3 }\end{array}$ \\
\hline C (22-year-old male) & $\begin{array}{l}\text { Delusions of persecution and } \\
\text { grandiose identity, nonaffective } \\
\text { verbal hallucinations about himself }\end{array}$ & No dysmorphisms & $\begin{array}{l}\text { Acute schizophrenia-like } \\
\text { psychotic disorder }\end{array}$ & $\begin{array}{l}\text { I.I Mb gain in } \\
7 q|1.2| q \mid I .22\end{array}$ \\
\hline
\end{tabular}

Abbreviations: CNV, copy number variant; ICD-I0, International Statistical Classification of Disease and Related Health Problems, I0th Revision; SD, standard deviation. 
may reveal novel recurrent microdeletion syndromes that, however, are nearly always accompanied with developmental delay and dysmorphisms, and do not seem to correlate with psychiatric symptoms. ${ }^{37,38}$ The counterpart microduplications in these regions often cause a much milder phenotype.

In conclusion, the results of this and other studies on the presence of CNVs in patients with psychotic disorders have not yet led to a further specification of their pathophysiology nor to breakthroughs in clinical strategies. Therefore, while genetic analysis should always be considered as part of the diagnostic equipment in neuropsychiatry, the application of genome-wide array analysis in patients with psychotic disorders is mandatory only in the presence of other clinical signs such as facial dysmorphisms or developmental delay.

\section{Acknowledgment}

This study is part of a collaborative project of the research group 'Psychopathology and Genetics'.

\section{Disclosure}

The authors report no conflicts of interest in this work.

\section{References}

1. Cuesta MJ, Peralta V. Integrating psychopathological dimensions in functional psychoses: A hierarchical approach. Schizophr Res. 2001;52: 215-229.

2. de Gracia Dominguez, Viechtbauer W, Simons CP, van Os J, Krabbendam L. Are psychotic psychopathology and neurocognition orthogonal? A systematic review of their associations. Psychol Bull. 2009;135:157-171.

3. McGrath J, Saha S, Welham J, El Saadi O, MacCauley C, Chant D. A systematic review of the incidence of schizophrenia: The distribution of rates and the influence of sex, urbanicity, migrant status and methodology. BMC Medicine. 2004;2:13-13.

4. Van Os J, Kapur S. Schizophrenia. Lancet. 2009;374:635-645.

5. Sullivan PF. The genetics of schizophrenia. PLoS Med. 2005;2:e212.

6. Mortensen PB, Pedersen MG, Pedersen CB. Psychiatric family history and schizophrenia risk in Denmark: Which mental disorders are relevant? Psychol Med. 2010;40:201-210.

7. Rutter M, Moffitt TE, Caspi A. Gene-environment interplay and psychopathology: Multiple varieties but real effects. J Child Psychol Psychiatry. 2006;47:226-261.

8. Van Os J, Kenis G, Rutten BPF. The environment and schizophrenia. Nature. 2010;468:203-212.

9. Veltman JA. Genomic microarrays in clinical diagnosis. Curr Opin Pediatr. 2006;18:598-603.

10. Vissers LE, de Ligt J, Gilissen C, et al. A de novo paradigm for mental retardation. Nat Genet. 2010;42:1109-1112.

11. Bassett AS, Scherer SW, Brzustowicz LM. Copy number variations in schizophrenia: Critical review and new perspectives on concepts of genetics and disease. Am J Psychiatry. 2010;167:899-914.

12. Duan J, Sanders AR, Gejman PV. Genome-wide approaches to schizophrenia. Brain Res Bull. 2010;83:93-102.

13. O'Roak BJ, Deriziotis P, Lee C, et al. Exome sequencing in sporadic autism spectrum identifies severe de novo mutations. Nat Genet. 2011;43:585-589.

14. Verhoeven WMA, Egger JIM, Feenstra I. Genetic disorders and the autism spectrum. Clin Neuropsychiatry. 2011;8:219-224.
15. Kirov G. The role of copy number variation in schizophrenia. Expert Rev Neurother. 2010;10:25-32.

16. Itsara A, Cooper GM, Bake C, et al. Population analysis of large copy number variants and hotspots of human genetic disease. Am J Hum Genet. 2009;84:148-161.

17. Vermeesch JR, Balikova I, Schrander-Stumpel C, et al. The causality of de novo copy number variants is overestimated. Eur J Hum Genet. 2011;19:1112-1113.

18. Arguello PA, Gogos JA. Genetic and cognitive windows into circuit mechanisms of psychiatric disease. Trends Neurosci. 2012;35: $3-13$.

19. Andreasen NC, Flaum MC, Arndt S. The comprehensive assessment of symptoms and history (CASH): An instrument for assessing diagnosis and psychopathology. Arch Gen Psychiatry. 1992;49:615-623.

20. Kay SR, Fiszbein A, Opfer LA. The Positive and Negative Syndrome Scale (PANSS) for schizophrenia. Schizophr Bull. 1987;13: 261-276.

21. Guy W. ECDEU Assessment Manual for Psychopharmacology Revised. NIMH Publication DHEW Publ. NO (Adm) 76-338. Bethesda, MD: National Institute of Mental Health; 1976:217-222.

22. Skodol AE, Rosnick, Kellman D, et al. Development of a procedure for validating structured assessment of Axis II. In: Oldham JM, editor. Personality Disorders: New Perspectives on Diagnostic Validity. Washington, DC: American Psychiatric Press; 1991:43-70.

23. World Health Organization. The ICD-10 Classification of Mental and Behavioural Disorders. Geneva, Switzerland: World Health Organization; 1992.

24. De Leeuw N, Hehir-Kwa JY, Simons A, et al. SNP array analysis in constitutional and cancer genome diagnostics - copy number variants, genotyping and quality control. Cytogenet Genome Res. 2011; 135:212-221.

25. Maiti S, Kumar KH, Castellani CA, O'Reilly R, Singh SM. Ontogentic de novo copy number variations (CNVs) as a source of genetic individuality: studies on two families with MDZ twins for schizophrenia. Plos One. 2011;6:e17125.

26. Ohtsuki T, Horiuchi Y, Koga M, et al. Association of polymorphisms in the haplotype block spanning the alternatively spliced exons of the NTNG1 gene at 1p13.3 with schizophrenia in Japanese populations. Neurosci Lett. 2008;435:194-197.

27. Stefansson H, Rujescu D, Cichon S, et al. Large recurrent microdeletions associated with schizophrenia. Nature. 2008;455:232-236.

28. Stone JL, O'Donovan MC, Gurling H, et al. Rare chromosomal deletions and duplications increase risk of schizophrenia. Nature. 2008;455: 237-241.

29. Fañanás L, Fuster C, Guillamat R, Miró R. Chromosomal fragile site 1q21 in schizophrenic patients. Am J Psychiatry. 1997;154: 716-716.

30. Brzustowicz M, Hodgkinson KA, Chow EW, Honer WG, Bassett AS. Location of a major susceptibility locus for familial schizophrenia on chromosome 1q21-q22. Science. 2000;288:678-682.

31. Rosa A, Fananas L, Cuesta MJ, Peralta V, Sham P. 1q21-q22 locus is associated with susceptibility to the reality-distortion syndrome of schizophrenia spectrum disorders. Am J Med Genet. 2002;114: 516-518.

32. Köhler M, Hirschberg B, Bond CT, et al. Small-conductance, calciumactivated potassium channels from mammalian brain. Science. 1996; 273:1709-1714.

33. Ni X, Valente J, Azevedo MA, Pato MT, Pato CN, Kennedy JL. Connexin 50 gene on human chromosome 1q21 is associated with schizophrenia in matched case-control and family-based studies. J Med Genet. 2007;44:532-536.

34. St Clair D, Blackwood D, Muir W, et al. Association within a family of a balanced autosomal translocation with major mental illness. Lancet. 1990;336:13-16.

35. Millar JK, James R, Brandon NJ, Thomson PA. DISC1 and DISC2: Discovering and dissecting molecular mechanisms underlying psychiatric illness. Ann Med. 2004;36:367-378. 
36. Verhoeven WMA, Tuinier S. Clinical perspectives on the genetics of schizophrenia: A bottom-up orientation. Neurotox Res. 2008;14: 141-150.

37. Koolen DA, Sharp AJ, Hurts JA, et al. Clinical and molecular delineation of the $17 \mathrm{q} 21.31$ microdeletion syndrome. J Med Genet. 2008;45: $710-720$.

38. Van Bon BWM, Mefford HC, Menten B, et al. Further delineation of the 15q13 microdeletion and duplication syndromes: A clinical spectrum varying from non-pathogenic to a severe outcome. J Med Genet. 2009;46:511-523.
39. Hehir-Kwa J, Egmont-Petersen M, Janssen I, et al. Genome-wide copy number profiling on high-density bacterial artificial chromosomes, single-nucleotide polymorphisms, and oligonucleotide microarrays: a platform comparison based on statistical power analysis. DNA Res. 2007;14:1-11.

\section{Publish your work in this journal}

Neuropsychiatric Disease and Treatment is an international, peerreviewed journal of clinical therapeutics and pharmacology focusing on concise rapid reporting of clinical or pre-clinical studies on a range of neuropsychiatric and neurological disorders. This journal is indexed on PubMed Central, the 'PsycINFO' database and CAS.
The manuscript management system is completely online and includes a very quick and fair peer-review system, which is all easy to use. Visit http://www.dovepress.com/testimonials.php to read real quotes from published authors.

Submit your manuscript here: http://www.dovepress.com/neuropsychiatric-disease-and-treatment-journal 